\title{
Normativity and Naturalism as if Nature Mattered
}

\section{Andrew Sayer, Lancaster University, UK, March 2019}

\section{Draft of paper to be published in Journal of Critical Realism}

The usual way of discussing normativity and naturalism is by running through a standard range of issues: the relations of fact and value, objectivity, reason and emotion, is and ought, and the so-called 'naturalistic fallacy' ${ }^{1}$, etc. This framing of the debate effectively sets up naturalism and realism to fail, making it seem that questions of what is good or bad, what we should do and how we should live have no defensible relation to how things are, including what kind of beings we are. It is a 'naturalism' that sees no need to say anything about or learn from nature. We can illustrate the absurdity of the approach by imagining the following scenario: We go to see a doctor to have our blood pressure taken. Unless we have read up on how to interpret blood pressure test results, we expect not only to be given two numbers, one over the other, but more importantly to be told whether it's good or bad, and if the latter, what we should do about it. We wouldn't think much of a doctor who said, "I can't tell you whether it's good or bad because that would be a value-judgement and would compromise my objectivity, and I can't tell you what to do because you can't deduce an ought from an is."

I have critiqued the standard, anti-naturalist views of normativity elsewhere and argued for a 'qualified ethical naturalism' that allows space for cultural variation and culturally-specific goods (Sayer, 2011, 2017). Here I want to take a different tack and develop an account of the biological underpinnings of normativity, a subject neglected even in many defences of naturalism. The main authors I draw upon are mostly virtue ethicists (Philippa Foot, Alasdair Maclntyre, Mary Midgley, Iris Murdoch, Martha Nussbaum, Charles Taylor, Bernard Williams) and neuroscientists, particularly Antonio Damasio. Although they are not normally considered critical realists, I wish to argue that it is possible to construct an account of normativity from their work that is consistent with $\mathrm{CR}$, and which can strengthen it. While CR literature has contributed valuable arguments to the debate, I shall argue that it has sometimes fallen into the very traps of epistemic fallacies, logicism and Cartesianism that it has identified so clearly. When it comes to normativity, CR hasn't been naturalist enough, referencing physics and chemistry but ignoring biology. Bhaskar's concept of 'four-planar being' is helpful though, in which "every social event is occurring simultaneously at each of four planes of social being. These are constituted by (a) material transactions with nature; (b) social interactions between people; (c) social structures sui generis; and (d) the stratification of the embodied personality" (Bhaskar 2016, p.83), where (d) includes the body's internal processes. I shall discuss some of the links or feedbacks between these planes.

I ask readers to put aside the usual definitions of ethical naturalism and moral realism. I will present a naturalistic account of normativity that attempts to explains how value

\footnotetext{
${ }^{1}$ Note Bernard Williams' comment on 'the naturalistic fallacy', "It is hard to think of any other widely used phrase in the history of philosophy that is such a spectacular misnomer." (Williams, 1985, p.121).
} 
judgements have similarities to straightforwardly factual claims about what is the case in the world. The discussion will therefore cross a very different terrain from the usual ones of facts and values, is and ought. It will begin with biology, but it will not end there, for we are cultural beings, though here we need to treat cultures as providing not only different interpretations of the world but different forms of material practice and association. In moving from biology to culture we encounter not only stratification and emergence but downward causation. As we shall see, both these 'vertical' relations are important for understanding normativity.

I will begin by briefly summarising the standard assumptions made in many discussions of naturalism that in my view prevent us from understanding it. I shall then set out an alternative approach that begins with biological normativity, and how it enables the forms of normativity we associate with human social life. Next, I will briefly address the question of why we might regard biological normativity as relevant to judgements of what is good, before moving on to address the relationship between normativity with respect to social life and cultural practices and ethics. I will then conclude by restating the main themes and implications.

\section{How not to think about normativity:}

1. Reduce normativity to norms and imperatives and ignore evaluation.

2. Reduce 'ethical naturalism' to the belief that ought can be derived from is. ${ }^{2}$ Say nothing about nature.

3. Boil the issues down to the logical properties and relations of statements. Mistake the things of logic for the logic of things. ${ }^{3}$ Reject any inferences not based on deductive logic.

4. Conflate and confuse 'objective' in the sense of 'true' or 'truthful' with 'objective' in the sense of 'value-free'.

5. Reduce practical reason to theoretical reason. Commit the scholastic fallacy of projecting the contemplative, deliberative relation of the academic to the world onto ordinary people going about their business (Bourdieu, 2000). (See 3.)

6. Insist that value claims must be either conclusively verifiable or else arbitrary and merely subjective. Reject the good-enough on the grounds that it's not perfect. Imagine that unless we know everything about the good or well-being, we know nothing. Assume that unless every and any moral or ethical claim can be universal, none can.

7. Base naturalism only on physics or chemistry and ignore biology and psychology, bodies, health and ill-health. Discuss what is good or ethical without considering our nature as embodied, embrained, intensely social beings, not only capable but vulnerable and dependent.

8. Treat emotions and feelings as threats to reason and objectivity - as not about or deriving from anything, but as merely subjective projections onto the world.

\footnotetext{
2 E.g. Elder-Vass, 2010, p.35

3 The error of 'logicism', as Harré called it (Harré, 1970).
} 
9. In Cartesian fashion, disassociate mind from body, and treat the latter as something reason can and should 'rise above'. Acknowledge only those human characteristics that seem to be unique to humans, in particular the capacity for reason, and affect a stance of "deliberate ignorance" about any other aspects of human nature (Midgley, 1984, p.105). ${ }^{4}$

Accepting any of these makes it difficult if not impossible to understand normativity. It would take at least a book to counter each of them, though in a way, that is what I attempted to do in my Why Things Matter to People (Sayer, 2011), in order to defend a 'qualified ethical naturalism'. In what follows, I shall approach normativity and naturalism without making any of the above assumptions. Rather than repeat the critique I made of these assumptions in that book, I shall take a different route and begin with biology, though I believe it makes it clearer just why indeed things matter to people. Here some recent developments in neuroscience have been helpful in illuminating the relations of the biological, the psycho-social and the cultural. In what follows I draw particularly upon the work of Antonio Damasio. I should add that in so doing, I am sticking my neck out a lot further than before.

Just to allay any fears, beginning with biology needn't involve any disregard or devaluation of the human capacity for reason and choice, or of the special nature of human cultures in opening up vast possibilities of action and experience, and hence normative consideration, unavailable to other species. ${ }^{5}$ But these capacities for reasoning and for cultural development presuppose and are emergent effects of certain neurological and other biological capacities. To be rational animals, we have to be animals, albeit of a certain kind (Midgley, 2003). Our physiological processes are not incidental to what we consider to be uniquely human about us and acknowledging biology need not demean us. Moreover, along with a number of other species, we are social animals, physically and mentally dependent on and equipped for the challenges of living in groups. We should therefore resist the tendency to treat the biological and the social as mutually exclusive and opposed. To be sure, there are appalling cases of the mis-use of biology in understanding the social world, such as in eugenics and Nazism, but mis-uses should not drive out good uses. As embodied beings we cannot expect to be mentally and physically healthy or to be able to treat each other well if we do not pay attention to the kinds of beings we are. Further, as Margaret Archer has said, we are 'evaluative beings' (Archer, 2000; see also Keane, 2016). I shall show that normativity is very much to do with being, with life itself, and like Bernard Williams, I shall argue that normativity is primarily about evaluation and only secondarily about oughts (Williams, 1985).

\section{Biological normativity}

\footnotetext{
${ }^{4}$ In the case of poststructuralism, we might add: "Reduce normativity to a matter of 'normalising', and regard it wholly negatively, ignoring the contradiction involved in saying it's wrong to say anything is wrong.

${ }^{5}$ While some other animals exhibit cultural variation - differences in behaviour that are learned in specific sub-groups rather than genetically inherited - it seems to be of a much more limited form than that evident in human cultures.
} 
"You cannot have a plant or animal without certain quite definite things being good or bad for it." (Mary Midgley, 2003, p.54).

Living beings are characterised by homeostatic mechanisms. The survival of organisms depends on the maintenance of specific forms of internal organization and of certain flows of matter and energy across their boundaries (Damasio, 1999; 2018; Capra and Luisi, 2014). Homeostatic mechanisms are activated when the external flows or internal organization are threatened, making the organism react in ways that normally tend to perpetuate its functioning, so it continues to be able to do the things that an organism of its type can typically do. Thus, particular causal powers, such as those of the heart, are activated and regulated by other sets of causal powers which monitor their functioning and respond appropriately. ${ }^{6}$ Though a tree root does not have a 'goal' or still less a 'norm' of finding moisture, its growth tends to respond to differences in soil moisture in a way that enables it to do so and is conducive to the continued functioning of the tree's metabolism, and hence to successful reproduction and survival of the species. ${ }^{7}$ Our immune, endocrine (hormone) and nervous systems are examples of such mechanisms. Biological homeostatic mechanisms are themselves affected by genetic variation and environmental influences, working better in some individuals than others. ${ }^{8}$ We depend on them; for example, the nervous system is involved in controlling our fight-or-flight response.

With the aid of a nervous system extending throughout our body ${ }^{9}$, our brain continuously monitors our bodily functions and movements in relation to that environment, and regulates them, whether we realise it or not, directing us away from threats and towards opportunities and flourishing. Even if we deliberately seek out danger rather than safety, our homeostatic systems must be functioning adequately for this to be possible. While this capacity of the body to protect us from danger is obvious, it is easy to miss the other side of the coin, namely, that like many other 'higher' animals, we also have capacities for seeking opportunities that enable us to flourish. This goes beyond seeking familiar things like sources of food and shelter to exploring the unfamiliar: curiosity, in other words. This, too, makes sense in evolutionary terms.

'Autonomic systems' of the body are those that function without conscious direction. Although we may in some cases be able to modify their functioning intentionally, they may also override directions that endanger us, such as attempts at stopping breathing. It is therefore understandable that we should think of such powerful tendencies in terms of 'lifeforce' or 'drives'. ${ }^{10}$ Social scientists tend to be deeply suspicious of such terms because they can be mis-used: what are sometimes seen as irresistible natural forces may actually be behaviours that individuals can control, indeed they may be little more than culturally-

\footnotetext{
${ }^{6}$ While critical realists usually explain causation in terms of examples of causal powers that may or may not be activated, to be alive is to be dependent on causal powers that are continually active and difficult to stop or override.

7 I suggest this non-intentional seeking is an evolutionary precursor of curiosity, a capacity which notwithstanding its dangers allows the discovery of opportunities for survival and flourishing.

8 In some cases they may even be dysfunctional, as when an overly strong immune system attacks the body.

9 The brain is not a discrete or self-sufficient organ counterposed to the body, but part of several more extensive physiological systems. To acknowledge this, I will thus refer at times to the 'brain-body'.

${ }^{10}$ See also Spinoza's concept of conatus.
} 
validated behaviours. But that doesn't mean that such concepts can't sometimes be used legitimately, indeed it is hard to see how we could understand ourselves as living beings otherwise. As Francesca Michilini explains, Hegel argued that life is characterized by the 'activity of deficiency'. To stay alive our bodies continually have to respond to deficiency, lack, hunger, thirst, cold, heat, insufficient oxygen and so on. They do so 'as if' they had a purpose, though in fact they do not have one. "Life is inextricably bound up with what it lacks." (Michilini, 2012, p.137; Sayer, 2011), and need is fundamental to normativity (Barham, 2012). We are always moving between various mixes of suffering and flourishing, between things as they are, and as they might be, for better or worse, between states of lack, desire, yearning, and possible states of fulfillment. We might, however, question whether we should regard such forces as good, and what 'good' might mean here; I shall come to this later.

Homeostatic mechanisms produce corrective tendencies and so we might be tempted to agree with primatologist and ethologist Frans de Waal's claim that "corrections are by definition normative" (de Waal, 2013, p.227). This stretches the scope of normativity beyond things which we consciously notice or will, and so some may object that describing such mechanisms in this way imputes motives to mechanisms that don't have them, but which merely respond unknowingly. But again, they only act as if they have purposes. While it is important to note the difference between unwilled drives and intentions, we shouldn't overlook the power and importance of the former in keeping us alive and well, on the whole. Someone who has been denied food for a week desires food in the first place because of the sheer force of the objective 'bodily-ought' of hunger. This force does not depend on the will or on any kind of purpose or reasoning, and still less on logical relations between statements, but rather operates at a more elementary level and forces itself on their attention, recruiting the will, as it were, so the starving person also consciously seeks food. To be sure, human normativity should not be reduced to bodily normativity, but nor, I shall argue, should it be seen as wholly detached from it.

A dichotomous view of the relation between facts and values commonly intersects with Cartesianism, so that the body is restricted to the fact side, while values and normativity are associated exclusively with the mind: the body just is, it does things but has no values. Such a framework obstructs understanding of the relation between mind and our brain-bodies. As de Waal argues:

"Values are embedded in the way we are. It is sometimes thought that biology falls entirely on the "is" side of the moral equation, but every organism pursues goals" (de Waal, 2013, p. 164).

De Waal is playing fast and loose with the notion of 'goals' here. Few organisms appear to have goals, but they all have ways of prolonging their functioning in the face of certain ranges of external and internal changes. Humans do have goals, of course, but like other animals they also have autonomic processes, which keep them alive and generally healthy and enable them to do the things which philosophers have regarded as uniquely human. But the key thing which de Waal gets right is that values and valuation in an intransitive sense are embedded in the way we are, in life itself, in the bodily strivings, appetites and aversions that keep us alive, some of which we interpret and evaluate transitively. There is an important sense in which life itself is normative, and what we subjectively regard as good or bad is partly an interpretation of that intransitive normativity. Imagining that everything 
to do with values belongs in the subjective, transitive domain, as opposed to intransitive, objective, independent matters of fact, reduces matters of being to matters of knowledge a classic epistemic fallacy. Our subjective values are about something that is not reducible to the realm of consciousness, and their fallibility derives from the fact that there is something independent of them about which they may be mistaken. ${ }^{11}$

This independence, however, is only partial because of various kinds of downward causation that can, up to a point, give a self-fulfilling character to transitive valuations. Thus, if we repeatedly summon up bad memories and thoughts, so it becomes a habit (through establishing major neural pathways), then this can have a depressing effect on our immune systems, on the way we interact with others and hence how others respond to us, and on our physical health. Positive thinking and placebos or negative thinking and nocebos can sometimes be downwardly causally efficacious and affect our physical and mental health.

Autonomic regulation in the brain-body ${ }^{12}$ may contingently give rise to sensations or feelings, which we may or may not register consciously. If the idea of having bodily sensations or feelings of which one is unaware seems strange, notice how we can sit for hours working at a computer without noticing the feeling of our weight in the chair or our skin's contact with our clothes. Similarly, at times we may not be aware of, or 'in touch with' our emotions because we are preoccupied with other things. Feelings give us indications of tendencies towards flourishing or suffering; they have 'valence'. Emotions assign value to experiences. They both monitor and motivate us. Hence, they are both world-guided and world-guiding. ${ }^{13}$ Feelings are not simply subjective products of the mind, though we can subjectively interpret them in different ways. ${ }^{14}$ When we do register these bodily processes consciously this may have the effect of feeding back to those processes, amplifying or dampening them. This again is an example of downward causation from emergent powers back to the structures and processes on which they depend.

In 'higher' animals the brain is able to 'map' or represent the internal and external objects and events it senses via the body, though this happens automatically and continuously; consciousness is not necessary for this. Experiences affect the way in which neural pathways develop, and in turn this affects subsequent responses to the world. Thus, a dog that was abused may be unable to relax in the presence of humans. A person's behaviour may be affected by traumatic events - perhaps ones that they cannot recall because they occurred in infancy before they had developed a capacity for memory. Because the brain is plastic there are causal loops between behaviours or experiences and our acquired dispositions, though once acquired, some dispositions are difficult to change. As Bessel van der Kolk puts it, "the body keeps the score" (van der Kolk, 2014). Consequently, our biological processes cannot be taken simply as an unchanging given. The biological causal powers and

\footnotetext{
11 On this 'aboutness' of morality and ethics I am in agreement with Andrew Collier (1999; 2003). Of course, as we can reflect on our thoughts and memories, consciousness can also be intransitive too.

12 See footnote 9.

13 This distinction is usually made with reference to statements (e.g. Williams, 1985), but note here it applies to the body, to intransitive processes.

${ }^{14}$ This distinction, which is entirely consistent with critical realism, is made by Damasio. He conceptualises emotions not as subjective feelings but as the very workings of homeostatic systems, some of which contingently give rise to objective feelings or sensations, some of which we contingently notice, transitively.
} 
affordances that allow social life are themselves affected by what we do and experience, which in turn is at any time constrained and enabled by our plastic brains.

The brain not only maps or represents events and objects but also registers or 'values' them positively, negatively or neutrally, producing what Damasio calls 'somatic markers' (Damasio, 2006). This may happen without our being aware of it. Thus, pleasant or hurtful experiences are marked as such, creating dispositional representations, with the consequence that future encounters with similar events prompt similar spontaneous responses. For example, experiences of punishment and reward in childhood tend to generate dispositions that prompt decisions and actions of particular kinds. These responses are typically much faster than processes of reasoning. Most strikingly, the amygdalae (in the lower brain), which figure prominently in emotional responses, both pleasant and unpleasant, can trigger physical responses to danger within 14 and 400 milliseconds, long before we consciously notice the source of the danger. Somatic markers may impinge on our consciousness or influence us subconsciously. In the former case, these intransitive, normative bodily promptings may be overridden in deliberating and decision-making, but insofar as they have kept us safe in situations similar to new ones it is often wise to take them seriously in practical reasoning. As we go about our business, they contribute to what Iris Murdoch called the ongoing "work of attention" which "imperceptibly . . . builds up structures of value round about us ... [so] ... that at crucial moments of choice most of the business of choosing is already over (Murdoch, 1970, p.36).

Mind, Damasio argues, is an emergent property of the brain-body's monitoring, representational and regulatory systems (Damasio, 1999). Among other things, mind produces an awareness of some of these processes, particularly feelings, and an awareness not only of objects and events but of a relation between self and object - so that I sense that I am in this situation observing this object. Whereas homeostatic mechanisms operate directly, in an unmediated way, as when the release of a hormone triggers a response in an organ, mind allows a distance to be introduced between stimulus and response, a realm of contingency where there is scope for interpretative differences, comparison and reflection, creativity and cultural variety. It thereby enables reflexivity and more complex evaluations of situations, including those concerning relations to others - the prime subject of ethics. It also allows the formation of goals or purposes, including those that respond to the feelings created by purposeless homeostasis. It thereby allows for reflexivity. This ability to consider ourselves in relation to our situation also allows us to stand back from our desires and engage in second order evaluation of our goals themselves - 'strong evaluation', as Charles Taylor calls it (Taylor, 1989; Archer, 2000). ${ }^{15}$

Most basically, bodily normativity is involved in avoiding danger and finding safety and opportunities that allow the body to survive and flourish. This capacity is innate, though not fixed. Thus, newborns cry when they are hungry or abandoned and they seek attachment and are intensely interested in faces and facial expressions as indicators of safety and danger. They are not merely sponges that happen passively to absorb social influences. The newborn's body responds to smiling faces and gentle, prosodic voices differently from fierce

\footnotetext{
15 This is a drastically abbreviated version of Damasio's account of the origins of consciousness and sense of the self, omitting in particular the role of memory.
} 
expressions and harsh, monotone voices (Porges, 2011) ${ }^{16}$ At this level they are already social beings by virtue of their physiological, including emotional, responses to others. The infant's most basic evaluative, emotional responses to the world are then 'tuned' through their attachments to their primary carers, through the way in which they are held, responded to, soothed or aroused and introduced to the world. Attachment "helps the immature brain use the mature functions of the parent's brain to organise its own processes" (Siegel, 1999 p.67). (Equally, neglect and abuse have lasting effects on infants' subsequent development.) Our evaluative responses to the world are not simply products of reasoning or cultural meanings, but of the way our somatic markers and evaluative dispositions have been trained, even before we learn a language, so that depending on the quality of the attachment relations, we are emotionally stable or neurotic, nervous or confident, adventurous or cautious, introverted or extroverted.

Attachment depends on care, and this too is grounded in physical responses as well as, for humans, conscious moral reasoning. Care can trigger the release of hormones, particularly oxytocin, that have a calming, pleasant effect on both parent and child. Hence, though it might be expected that biological normativity would be purely self-centred, as social animals we are susceptible to the contagion of emotions from others; some neuroscientists argue that so-called mirror neurons make us experience similar feelings to those felt by others whom we are observing (Rose and Abi-Rached, 2014). Further, repeated interactions with particular others create complementary neural pathways and dispositions in each partner and the formation of attachments; hence we are relational beings. Empathy and altruism are not purely products of reflection and reasoning but are grounded in human biology. The fact that social isolation, rejection and shame can seriously affect the body and its susceptibility to illness is also a reminder of our social nature.

Life itself is normative not just because as humans we cannot avoid evaluating circumstances and thinking what we ought to do, but in the more basic, non-conscious sense applicable to all living organisms. Human normativity includes but goes beyond this, taking advantage of the affordances we acquire as our brain-bodies develop (Keane, 2016). Before addressing how it does so, this is a good place to say more about what biological normativity might have to do with ideas of what is good or bad.

\section{But what is good about it?}

Even if one accepts the broad outlines of this account of biological normativity and acknowledges there are clear tendencies, drives and impulses in the behaviour of organisms, including humans, one could still ask why certain bodily states are deemed good and others bad? And given that I have referred to 'flourishing' at various points, it might be objected that I have already smuggled in a normative premise without providing a justification.

\footnotetext{
${ }^{16}$ As Porges shows, this subconscious, physical response continues into later life, affecting our heart rate, activating or de-activating our fight or flight responses, and affecting our ability to engage with others, even at the basic level of being able to listen to what they say (Porges, 2012; see also Claxton, 2015; van der Kolk, 2014). These are some ways in which human biology is social.
} 
Here we must note the diverse meanings of 'good' or 'the good' (and 'bad'). First, we need to acknowledge that they are 'thin' terms that, on their own, leave us with no idea of whether to accept them; they inevitably seem arbitrary; in the context of ethical matters they are "empty moral words", as Murdoch called them (Murdoch, 1940, p.40). But if applied to bodies, actions or roles they may lose this arbitrariness. ${ }^{17}$ Thus, if 'good' or 'bad' are used with reference to bodily organs ('good muscle tone', 'a bad heart'), or activities and roles ('good teaching', 'bad parenting'), then it becomes clearer what criteria might be relevant to making a judgement about their justification, and how we might empirically check this out.

As regards biological or 'natural normativity', as Philippa Foot terms it, an animal is in a good state or flourishing if it is able to do what is normally possible for an animal of its type: for a dog it would include being able to run; for a 5-year old child it would include being able to speak and interact with others (Foot, 2001; see also Maclntyre, 1999). A dog with a broken leg, or a child that is catatonic, is not flourishing. ${ }^{18}$ This criterion is not reducible to an act of mere 'commendation' on our part, nor is it, as in emotivism, a function of the observer's (evaluator's) psychological state (Foot, 2001, p.37).

Of course, a determined sceptic might still question why, say, blocked coronary arteries, catatonia, or child abuse should be seen as bad? Isn't Foot's criterion an arbitrary convention? But such a sceptic would have misunderstood what good means in the context of bodily normativity, and courted absurdity in suggesting that evaluations of health have nothing to do with what they are about. The unreasonable sceptic would have to ignore the inherent normativity of life - that you can't have a plant or animal without certain things being good or bad for it. The absurdity also lies in implying that the very basis of life should have no influence on what we think or do, and that what we do is free of consequences: anyone who took such an idea seriously would not survive for they would be indifferent to danger and their own needs. In other words, such irrealist positions imply massive theorypractice contradictions.

'Good' and 'bad' are on some occasions shorthand for 'thick ethical concepts' like 'kind', 'cruel', 'brave', 'cowardly, 'selfish', 'generous', 'just' or 'unjust', 'abusive', 'exploitative', or 'racist', the meanings of which are simultaneously and indivisibly descriptive and evaluative, so their use is not arbitrary but appropriate or inappropriate according to the characteristics of the actions and situations to which they refer (Williams, 1985, p.216-17; see also Putnam,

\footnotetext{
${ }^{17}$ Here I am dealing with normativity with regard to life - biological and socio-cultural, personal - and not with evaluations of objects and their qualities, as in 'a good bed', where the criteria are instrumental. While animals or other people may also be viewed instrumentally as good or bad for our purposes, unlike they inanimate objects they have consciousness, which is why animals but not coats can be oppressed.

${ }^{18}$ Of course, as Charles Taylor points out, in some cases there may be overriding reasons for evaluating health negatively, as we might for regards the health of the ebola virus; these accept the positive valuation of health of that organism but argue that there is an overriding reason for trying to kill it. To undermine particular evaluations of health we would presumably have to show that the understanding of the functioning of the organism was mistaken in some way. While these understandings do not logically entail any particular ought, they set up a particular 'value-slope' that suggests that it would be unreasonable not to act in accordance with it (Taylor, 1967). Logical deduction is not the only kind of inference that we can rely on in life (fortunately!), and refusing any other kind puts us in the position of the perverse doctor of our opening scenario.
} 
2002). If I claim that 'millions of people are suffering in Syria', that is simultaneously a description and an evaluation of the situation. Like any factual claim it is fallible, and it could be checked out empirically. But it is also an evaluation: if you don't know that suffering is bad, you don't know what it is. Possible alternative descriptions of the situation which lacked any evaluative content would either euphemise and hence mis-describe it (as in references to 'collateral damage') or, if reflected on, come to take on the evaluative load associated with words like 'suffering'.

\section{From biology to culture and reason}

We need to address how natural and socio-cultural normativity inter-relate. To move from biology to society and culture is to move between ontological strata. One might assume that this stratification and emergence would allow us to discuss these levels separately, in sequence. But it will be apparent that in discussing human biology and normativity I have already had to refer to consciousness, reason and culture as emergent from our biology. The discussion of these topics couldn't be wholly postponed until we had done with biology precisely because of the prominent role of downward causation - 'the impact back' of social experience on our brain-bodies, in shaping the kind of beings we become in life. But even if we accept Foot's use of terms like good and flourishing in relation to an account of biological normativity, more needs to be said about the difference that the capacity for cultural differentiation and elaboration makes in producing additional, emergent forms of normative consideration.

Whereas other species have a relatively fixed relation to their environment, that is, one where homeostasis is dominant, the capacity for reasoning affords us a vast range of possibilities, in which, as Marx saw, through changing our environment and its influences upon us, we change ourselves. It opens up a realm of elaboration and development that gives us ever enlarged powers, albeit not ones that can ever escape the constraints of biology, contrary to the view of humans as beings with no nature, able to float free of such lowly matters. Modernity's disregard of nature has produced results that threaten our future existence. ${ }^{19}$ So even when we are considering reason and culture, and the specific kinds of normativity they foster, we cannot ignore biological normativity. For example, as Damasio has shown, emotions are crucial for making us pay attention to problems and opportunities and hence for making good decisions and being able to function socially; individuals who have brain damage that limits certain emotional responses may remain perfectly capable of solving logical problems but have great difficulty in making decisions and functioning socially (Damasio, 2006). Much of what has traditionally been attributed simply to our capacity for logical reasoning and dispassionate observation is owed to the guidance provided by our somatic markers and emotions. ${ }^{20}$

In recent years many psychologists and others have described human behaviour as involving two elements: a fast-acting response based upon acquired dispositions and emotions, and a

\footnotetext{
19 There are parallels between our disastrous disregard of external nature in modern society, and our disregard of the body - 'inner nature' - in philosophy and social science.

20 See also Archer's apt comments on the "emotional lobotomy" of "Modernity's man" (Archer, 200, p.85).
} 
slower response based on reflection and reason (Kahneman, 2011; Greene, 2014; Keane, 2016). There are similarities between this 'dual process theory' and approaches to explaining behaviour that combine habitus and reflexivity (Archer, 2009). Both may aid good decision-making, the former more in familiar situations, the latter in novel ones. Again, it is crucial to resist the tendency to see emotions as opposed to reason. They are in continual dialogue, sometimes in tension, sometimes in harmony; which is dominant in influencing thought and action may vary, depending on the situation.

As humans we tend to develop concerns and commitments, and attachments to significant others - an emergent property of our nature as social animals (Archer, 2000; Sayer, 2011). Our involvement in them can affect us deeply, not merely at an intellectual level but emotionally as sources of meaning, satisfaction, and recognition, such that to lose them or have them threatened affects our well-being, indeed our sense of self. Bereavement, for example, cannot be understood as pertaining purely to the level of reason and meaning. Such relations are ones in which our bodies are very much involved, indeed emotions are often 'bodily commentaries' on our concerns (including attachments) (Archer, 2000). When we ask someone 'how they are' we expect not only to know about their physical health but how their concerns are faring. Though there is nothing in a newborn's nature that need make it later become committed to, say, art or politics, those activities may one day, through downward causation, come to recruit its physical and emotional capacities in ways that have a lasting effect on how it develops and responds to the world, and on what it values.

Cultures - in a broad sense of particular ways of life with their associated artefacts, material and social structures and forms of sense making - provide not only interpretations of the world but involve remarkably diverse ranges of practices that provide objects of evaluation and affect well-being. Practices such as hunting, farming, teaching, construction, science, art, religion, music, literature, sport, crafts and so on have their own internal goods and standards of excellence that aren't reducible to criteria relating to the body, though to varying degrees they include them (Maclntyre, 1985). Through downward causation they may have significant effects on physical and mental health, for they recruit and elaborate emotional and other physical responses. Cultural life is embodied, and our bodies become responsive to cultural phenomena, insofar as they are capable of doing so. In some cultural practices, such as music, dance, religion and literature, the active recruitment of the body and emotions is of central importance; in others, like mathematics or astronomy, less so. Generally, it is more important in practical reason than theoretical reason, though if we live under the threat of danger so our fight and flight response is continually switched on, we cannot achieve the calm and focus to be able to concentrate on theoretical issues. Engaging in theoretical reason may also impact back on us by becoming a source of fulfilment, recognition and happiness that recursively motivate further engagement.

So we can think of cultural practices as extraordinarily rich elaborations of emergent possibilities afforded by our biological make-up and environment, that allow activities and experiences that recursively modify our brain-bodies. They are typically open-ended, allowing continual unfurlings of elaborations and innovations. 'Flourishing' in this context suggests diversity, abundance and vibrant activity, as in statements such as 'the city has a flourishing arts scene'; this Aristotelian sense implies not merely surviving or avoiding 
suffering but being able to develop and use one's capacities fully. It should be noted however that not all forms of cultural elaboration enable flourishing: fascism, violence and paedophilia do not, for example, and for the telling reason that they prevent those they target from doing what people, as both biological and cultural beings, are typically able to do. Cultures expand the possible sources of flourishing and suffering open to us.

Cultural elaboration also allows flourishing in a richer sense of not merely being able to do and be a fixed range of things typical of our species, but to develop new capacities, to learn and innovate. As historical beings, we therefore tend to evaluate human flourishing according to criteria that change as particular groups or cultures develop, so that for example, once literacy, education or immunisation against diseases are established in some groups and bring new benefits, they are likely to be seen as desirable for all, albeit precisely because as human beings we still have similar rather than radically different potentials. Hence there is a parallel with Foot's criterion of the good with reference to natural normativity. ${ }^{21}$

In all these respects, we must add that our evaluations are strongly influenced by available discourses, institutions, power relations, and 'norm circles', as Dave Elder-Vass calls them (Elder-Vass, 2012), which provide us with ways of thinking and seeing, often backed up with rewards and penalties. But all of these depend on being able to create and recruit dispositions and feelings that in turn are enabled by our brain-bodies, and the ease with which they do so will be affected by how they relate to our well-being; repressive norms may provoke resistance. Even norms regarding historically-specific social constructions such as property rights and the law, are justified according to criteria which include their implications for psychological and physical well-being. Some norms formalize valuations that are or appear to be purely arbitrary; for example, regarding dress codes or how a table should be set for a meal. Yet even where they seem to bear no relation to what is necessary for well-being, they can become invested with associations of propriety, and recruit emotions accordingly, such that transgression of the norms can trigger responses of offence and outrage, which of course help maintain the norms and associated power relations. Hence, while normativity in human societies goes beyond biological normativity, it does not wholly escape it.

Normative evaluations and decisions in social life often confront difficulties that go far beyond those posed in relation to physical well-being, because of the need to consider others, the sheer complexity and interconnectedness of modern societies, and the diverse demands upon our time and attention, and the well-being of other species and the biosphere. Here it is common to find situations where we may decide that we should forego the pursuit of some particular good - for example, our own health - for the sake of some more important good. Goals that might seem defensible in isolation may not be pursued if, in the bigger picture, there are overriding considerations. As Aristotelians emphasize, wellbeing requires the attainment and balancing of a number of different, incommensurable goods, for example, liberty, self-care, family, friendships, work and other commitments;

\footnotetext{
21 Maclntyre extends Foot's way of thinking about natural normativity into the socio-cultural realm, with regard to roles, where "Good is ascribed . . . both to what benefits human beings as such and to what benefits human beings in particular roles within particular contexts of practice." (Maclntyre 1999, p. 65).
} 
hence the importance of strong evaluation in our lives. Further, particular goods and bads may be interdependent or entangled so that we are faced with dilemmas. On top of all this, given our neuroplasticity and physical adaptability, our preferences may be adaptive, so we make a virtue of necessity. No wonder then that normative evaluations of how to live are so contestable.

\section{Conclusions and implications}

None of the above means that we can logically deduce an ought from a purely factual, nonevaluative statement, but that is an absurdly reductive way of thinking about normativity and naturalism. But then, since ought implies can, it would make sense to pay more attention to the kind of beings that we are. Instead of assuming that the only thing that matters about us is the one capacity that philosophy values above all, our ability to reason, we need a naturalism that lives up to its name and takes nature seriously. Remaining within the standard is-ought framework for discussing normativity and naturalism renders unintelligible how practical reason enables people to survive and often flourish.

Hence, much of this paper has been a description of how normativity works in practice, in the lives of people as embodied, evaluative, social beings, rather simply a discussion of how we should evaluate things according to standards of rigorous reasoning - the usual focus of philosophical discussions of normativity. But then naturalism breaks down the divide between science and philosophy; it should also encourage dialogue between human biology, especially neuroscience, and social science, indeed we need 'biopsychosocial' studies. Insofar as we discuss reason, we need to think of it not only in terms of the 'horizontal' relations among statements but in terms of 'vertical relations' of attentiveness to the world, including what our emotions are telling us (Sayer, 2011; see also Collier, 1999).

The kind of naturalism I have defended here takes us beyond the explanatory critiques of falsely-based beliefs and actions à la Bhaskar's The Possibility of Naturalism, to critiques of forms of ill-being and suffering and restricted flourishing (Bhaskar, 1978). While the former can be derived without any reference to nature in terms of biology, the latter can only be made sense of through a naturalism that treats normativity in everyday life as an emergent outgrowth of biological normativity. Life itself is normative, and hence, in Andrew Collier's expression, already 'valuey' (Collier, 2003). Biological normativity involves valuations and oughts that come from the body, and which as feelings may contingently become the object of conscious valuations. The latter are made via the concepts and value frames available to us, so there are different ways of interpreting any given feeling, some better than others. We may decide to ignore or override such valuations, for whatever reason, but we simply wouldn't survive if we always did so.

The account has been a realist, objectivist one in that it regards well-being, or flourishing as objective states of being about which we make 'subjective' judgements. These are fallible, because they are about something that is generally independent of the judgement. This of course is a classic realist position. Thus, we may think we are healthy when we are not; but then again, for it to be possible for us to survive we must at least have a reasonable idea of basic elements of flourishing and suffering. The meaning of 'good' is, in many cases, related 
to well-being, as an objective state, as an intransitive object. Subjective states can also be treated as intransitive objects for us, and because they can have an effect on our bodies through downward causation, subjective happiness can also be seen as a necessary though far from sufficient part of objective well-being. To be deluded about one's condition, such that we fail to recognise our well-being or ill-being, would itself count as an element of restricted well-being. In effect, the concept of adaptive preferences acknowledges this. Significantly, attempts to conceptualise and measure objective well-being sometimes include assessments of subjective well-being. ${ }^{22}$

Given that the mind and socio-cultural phenomena are emergent from biological phenomena, it might seem that we could get away with merely taking the latter as a given, as much existing social science and philosophy does. This might seem justified by analogy with the relation between social science and physics: we don't have to learn physics in order to understand social phenomena, because even though social behaviour takes advantage of physical laws it doesn't alter them. But human biology is different: because the sociocultural is dependent on the biological and because our actions, thoughts and subjective feelings impact back on our brain-bodies and their properties, which then constrain and enable our actions and thoughts in new ways, we cannot treat the stratification of reality as a justification for ignoring biology, especially neuroscience. ${ }^{23}$

As regards ethical theory, our naturalist approach supports theories that acknowledge that emotions and reasons need not be opposed, and that there is and should be a continual dialogue between them. In this respect it is close to the moral 'sentimentalism' of the Scottish Enlightenment, though more of Smith than Hume. It also supports virtue ethics with its emphasis on "internalized dispositions of action, desire and feeling" (Williams, 1985, p.35) and an Aristotelian concept of flourishing, as elaborated in the capabilities approach (Sen, ????; Nussbaum, 2000). Care ethics highlights the importance of attending to the cared-for as embodied beings whose capacities and vulnerabilities are strongly influenced by the kind of care they are given and the attachments they form; in effect it seeks to promote flourishing by encouraging beneficial kinds of interpersonal interaction and downward causation that help the brain-body function successfully. Not surprisingly, there is an emerging literature on care that draws on neuroscience (e.g. Abbott and Burkitt, 2015; van der Kolk, 2014; Doidge, 2007).

Although every experience has some impact on the brain-body, whether we realise it or not, it is never a blank slate on which anything can be written. Neuroplasticity does not mean we can be changed in just any way, or that all impacts on us are reversible (think of trauma and PTSD). ${ }^{24}$ At any moment in our life, our inborn and acquired causal powers and

\footnotetext{
22 UNICEF's (2007) Child Poverty in Perspective: An Overview of Child Well-Being in Rich Countries. https://www.unicef-irc.org/publications/445-child-poverty-in-perspective-an-overview-of-child-well-being-inrich-countries.html

${ }^{23}$ While I have long argued for a postdisciplinary approach that works to remove boundaries between the various social sciences, I hadn't seen any necessity for dialogue between biology and the social sciences (Sayer, 1990). I have now changed my mind.

${ }^{24}$ As Norman Doidge puts it, "The plastic paradox is that the same neuroplastic properties that allow us to change our brains and produce more flexible behaviours can also allow us to produce more rigid ones (Doidge, 2007; p. 242)
} 
susceptibilities constrain and enable how we respond to social processes such as discourses and practices and their powers and susceptibilities; the resulting actions then renew or change those capacities. The unfolding of the interaction between body and environment, both physical and social, must be understood as examples of morphogenesis (Archer, 2000). We are born with drives and aversions and certain capacities for relating to others in prosocial ways as well as seeking our own self-interest, but how these capacities are developed depends on how our lives go from the start. As Webb Keane puts it

"if the sources of the emotions lie in universals of human neurophysiology, their distinctively ethical character is only brought into focus [I would add 'and recruited and shaped'] through the dynamics of social interaction." (Keane, 2016, p. 242).

As critical realists have argued, causation always involves at least two sides, in this case, the capacities of brain-body and mind and the events, structures and experiences it encounters. It is time for social scientists and philosophers to stop treating socio-cultural phenomena as unilaterally efficacious and to take our nature as embodied social beings seriously.

\section{Acknowledgement}

Thanks - with the usual disclaimer - to Celia Roberts and Adrian Mackenzie for discussions of some of these issues.

\section{References}

Abbott, R. and Burkitt, E. (2015) Child Development and the Brain, Bristol: Policy Press Archer, M.S. (2000) Being Human, Cambridge: Cambridge University Press

Archer, M.S. (ed) (2009) Conversations about Reflexivity, London: Routledge

Barham, J. (2012) 'Normativity, Agency and Life', Studies in History and Philosophy of Biological and Biomedical Sciences, 43, (1) pp. 92-103.

Bauer, M. (2015) 'Normative Characterization in Biological and Cognitive Explanations' Theoria, 30/2, pp.271-286

Bhaskar, R. 1998. The Possibility of Naturalism. London: Routledge.

Bhaskar, R. and Norrie, A. (1998) 'Introduction: Dialectic and dialectical critical realism', in Critical Realism: Essential Readings, ed. Archer, M., Bhaskar, R., Collier, A., Lawson, T. and Norrie, A., Routledge, pp. 561-574

Capra, F. and Luisi, P.L. (2014) The Systems View of Life: A Unifying Vision, Cambridge:

Cambridge University Press

Claxton, G. (2015) Intelligence in the Flesh, New Haven and London: Yale University Press Collier, A. (1999) Being and Worth, London: Routledge

Collier, A. 2003. In Defence of Objectivity, London: Routledge.

Damasio, A. (1999) The Feeling of What Happens, London: Vintage

Damasio, A. (2006) (Rev.Edn) Descartes' Error, London: Vintage

Damasio, A. (2018) The Strange Order of Things: Life, Feeling, and the Making of Cultures, NY: Pantheon

De Waal, F. (2013) The Bonobo and the Atheist, NY: W.W.Norton

Doidge, N. (2007) The Brain that Changes Itself, London: Penguin

Elder-Vass, D. (2012) The Reality of Social Construction,

Elder-Vass, D. (2010) 'Realist critique without ethical naturalism and moral realism', Journal of Critical Realism, 9.1 pp.33-58 
Foot, P. (2001) Natural Goodness, Oxford: Oxford University Press

Harré, R. (1970) Principles of Scientific Thinking, London: Macmillan

Kahneman, D. (2012) Thinking Fast and Slow, London: Penguin

Keane, W. (2016) 'Ethical Life: Its Natural and Social Histories, Princeton, NJ: Princeton

University Press

Maclntyre, A. (1985) After Virtue, London: Duckworth

Macintyre, A. (1999) Dependent Rational Animals, London: Duckworth

Michilini, F. (2012) 'Hegel's notion of natural purpose', Studies in History and Philosophy of Biological and Biomedical Sciences, 43, (1) pp.133-139

Midgley, M. (1984) Wickedness: A Philosophical Essay, London: Routledge and Kegan Paul Midgley, M. (2003) Heart and Mind, Routledge

Moss, L. and Nicholson, D.J. (2012) 'On nature and normativity: normativity, teleology, and mechanism in biological explanation', Studies in History and Philosophy of Biological and Biomedical Sciences, 43, (1) pp.88-91.

Murdoch, I. 1970. The Sovereignty of Good. London: Routledge.

Nussbaum, M.C. (2001) Upheavals of Thought, Cambridge: Cambridge University Press

Nussbaum, M.C. (2013) Creating Capabilities, Cambridge, MA: Harvard University Press

Porges, S. W. (2011) The Polyvagal Theory, NY: W.W.Norton

Putnam, H. (2002) The Collapse of the Fact-Value Dichotomy. Cambridge, MA: Harvard

University Press

Rose, N. and Abi-Rashed, J. (2014) Neuro, Princeton, NJ: Princeton University Press

Sayer, A. (2000) 'For Postdisciplinary Studies: Sociology and the Curse of Disciplinary

Parochialism/Imperialism', in Eldridge, J., Maclnnes, J., Scott, S., Warhurst, C., and Witz, A., (eds) Sociology: Legacies and Prospects, Durham: Sociologypress, pp.85-97

Sayer, A. (2011) Why Things Matter to People: Social Science, Values and Ethical Life, Cambridge: Cambridge University Press

Sayer, A. (2017) 'Values within reason', Canadian Review of Sociology, 54 (4) pp.468-475

Sen, A. 1999 Development as Freedom, Oxford, Oxford University Press

Siegel, D. (1999) The Developing Mind: How Relationships and the Brain Interact to Shape Who We Are, NY: The Guilford Press

Smith, A. [1759] 1984. The Theory of Moral Sentiments. Indianapolis, IN: Liberty Fund.

Taylor, C. [1967] 1973. "Neutrality and Political Science." Pp. 139-70 in The Philosophy of Social

Taylor, C. (1989) Sources of the Self, Cambridge: Cambridge University Press

Explanation, edited by A. Ryan. Oxford: Oxford University Press.

Van der Kolk, B. (2014) The Body Keeps the Score, London: Penguin

Wade, M. (2019) Risky disciplining: On interdisciplinarity between sociology and cognitive neuroscience in the governing of morality, European Journal of Sociology,

Williams, B. (1985) Ethics and the Limits of Philosophy, London: Routledge 